Revue d'histoire de l'enfance « irrégulière »

Le Temps de l'histoire

7 | 2005

Enfermements et éducations

Les enfants de Cellule. La construction d'espaces et de temporalités de référence en lieu clos : un petit séminaire missionnaire auvergnat au XIXème siècle

François Backman

\title{
OpenEdition
}

Journals

Édition électronique

URL : http://journals.openedition.org/rhei/1143

DOI : 10.4000/rhei. 1143

ISBN : 978-2-7535-1645-8

ISSN : $1777-540 \mathrm{X}$

Éditeur

Presses universitaires de Rennes

Édition imprimée

Date de publication : 15 novembre 2005

Pagination : 173-197

ISSN : 1287-2431

Référence électronique

François Backman, « Les enfants de Cellule. La construction d'espaces et de temporalités de référence en lieu clos : un petit séminaire missionnaire auvergnat au XIXème siècle », Revue d'histoire de l'enfance « irrégulière » [En ligne], 7 | 2005, mis en ligne le 06 juin 2007, consulté le 04 décembre 2020. URL : http://journals.openedition.org/rhei/1143 ; DOI : https://doi.org/10.4000/rhei.1143 


\section{Les enfants de Cellule. La construction d'espaces et de temporalités de référence en lieu clos : un petit séminaire mission- naire auvergnat au XIXème siècle}

Cellule, commune du Puy-de-Dôme, diocèse de Clermont, 1856. La congrégation missionnaire du Saint-Esprit, fonde un petit séminaire, un orphelinat et une école à la suite de la donation d'une religieuse de l'ordre de la Visitation, Sœur Marie-Emmanuel Andraud. Lors des tractations avec les Pères spiritains, la visitandine vante les mérites de sa région : "Les jeunes gens qui se consacrent au Seigneur sont si nombreux dans les maisons que l'on rapporte qu'il s'en enrôle autant pour les congrégations de Frères que pour la conscription. " ${ }^{(2)}$

Quatre ans plus tard, en 1860, le Père Hubert, directeur de l'œuvre, retraçant ses premières années, note que " cette fondation était pleine d'avenir ; que le pays riche en foi, le serait conséquemment en vocations religieuses et qu'il importait de seconder sérieusement les beaux commencements du petit séminaire de Saint-Sauveur. Dès lors il fut résolu [...] qu’on y érigerait un [...] petit scolasticat de la Congrégation pour le recrutement de fervents et solides sujets ». ${ }^{(3)}$ La machine est lancée. Les spiritains tiendront école et orphelinat, mais surtout travailleront à faire naître des vocations pour l'Église par le biais du petit séminaire destiné à former de futurs prêtres diocésains, et pour leur congrégation au moyen du petit scolasticat. Cellule fait bel et bien office de condensé de ces écoles de vocations sacerdotales des chrétientés du Massif Central.

Dans une région encore vigoureuse sur le plan religieux, s'installe une congrégation en plein renouveau, qui imprime sa marque sur le diocèse pendant plus d'un siècle. Créée en 1703, la congrégation du Saint-Esprit fusionne

Abréviations utilisées : ACSSp (Archives de la Congrégation du Saint-Esprit, Chevilly Larue), ADPdD (Archives départementales du Puy-de-Dôme). Nos plus vifs remerciements au Père Gérard Vieira, archiviste de la congrégation du Saint-Esprit, ainsi qu’à Armelle Domas.
François

Backman $^{(1)}$

(1) Doctorant en

science politique

(2) Lettre au Très

Révérend Père, 29 décembre 1855, (ACSSp,

2 G 10 1a1). Concernant la sœur Marie-Emmanuel, voir Biographie de Soeur Marie-Emmanuel Andraud, Riom, imp.

G. Leboyer, 11 p.

(3) Notes et mémoire remis au Révérend Père Supérieur [...] sur les commencements du Petit scolasticat de St Sauveur, janvier 1860, (ACSSp, 2 G 10 1a2). Sur

l'Auvergne, réservoir à prêtres, voir la carte " diocèses de France et vocations missionnaires ", Les réveils missionnaires en France du Moyen Âge à

François Backman / p. 173 à 197 
nos jours (XIIème-XXème

siècles), Paris, Beauchesne,

1984 , p. 386. Le diocèse

de Clermont et ceux des

chrétientés du Massif

Central (Le Puy, Mende,

Rodez, Saint-Flour, Viviers)

sont, avec la région

bretonne, les zones les plus

fécondes en vocations

pour la période 1801-1940.

(4) Voir Paule Brasseur,

Paul Coulon, [dir.],

Libermann I802-I852. Une

pensée et une mystique

missionnaires, Paris,

éditions du Cerf, 1988,

938 p. ; Henry Koren,

Les spiritains. Trois siècles

d'histoire religieuse et

missionnaire, Paris, Beau-

chesne, 1982 ; Jean

Ernoult, Histoire de la pro-

vince spiritaine de France,

Paris, Congrégation du

Saint-Esprit, 2000. La con-

grégation est essentielle-

ment composée de prêtres

(Pères), secondés par

des Frères pour les assister

dans les tâches annexes,

voir Constitutions de 1878

(ACSSp, 3 C 2 3a9).
(5) Voir Charles Suaud,

"Splendeur et misère d'un

petit séminaire ", Actes de

la recherche en sciences

sociales, n 4 , août 1976 ,

p. 66-90, et La vocation.

Conversion et reconversion

des prêtres ruraux, Paris,

éditions de Minuit, 1978 ;

Jean-René Chotard,

Séminaristes... une espèce

disparue. Histoire et

structure d'un petit sémi-

naire, Guérande 1822-1966,

Sherbrooke, 1977 ; Louis

Secondy, « Place et rôle

des petits séminaires dans

l'enseignement secondaire

en France au XIXème

siècle ", Revue d'histoire de

l'Église de France, tome

LXVI, $n^{\circ} 177$, juillet-

décembre 1980. Une

bibliographie abondante

dans R. Naz, «Séminaire »,

Dictionnaire de droit cano-

nique, tome septième,

Paris, Letouzey et Ané,

1965, col. 929-952. Pour

une utile synthèse, voir

Marcel Launay, Les sémi-

naires français aux XIXème

et XXème siècles, Paris, édi-

tions du Cerf, 2003. en 1848 avec la Société du Saint Coeur de Marie fondée en 1841 par François Libermann et acquiert une vigueur nouvelle. Dès l'origine son but est double : la mission tournée principalement vers l'Afrique et vers la formation de prêtres. Farouchement attachée au siège de Pierre dès ses débuts, elle crée en 1853 le Séminaire français de Rome. Encouragée par l'intérêt croissant que la papauté porte aux missions, la famille spiritaine a donc le vent en poupe lorsqu'elle s'implante à Cellule, ayant bien compris la nécessité de disposer de bases arrière pour recruter et éduquer du personnel missionnaire. ${ }^{(4)}$ En formant de futurs prêtres diocésains et des missionnaires pour leur congrégation dans le Puy-de-Dôme, les spiritains constituent un relais de romanisation du clergé, en favorisant le progrès des doctrines, conceptions et pratiques ultramontaines.

Si les études, publiées ou non, sur les grands ou petits séminaires ne manquent pas, si la vocation sacerdotale est cernée sociologiquement, ${ }^{(5)}$ il peut paraitre néanmoins intéressant de suivre une partie du cursus de ces enfants de Cellule entrés dans le réseau spiritain comme petits séminaristes destinés aux terres lointaines ou aux paroisses auvergnates. À partir des exercices qu'ils réalisent (de la poésie latine à la rédaction de biographies), les petits séminaristes et petits scolastiques sont invités à (se) fabriquer un temps, un espace et une terre conformes à leur vocation. Ils sont amenés également à (se) créer un ciel peuplé de petits saints, Au-delà rempli de leurs camarades morts et de martyrs. Dans un établissement présentant nombre de caractères de l'institution totale, ${ }^{(\sigma)}$ ils sont enfermés et formés dans une certaine vision du sacrifice. Il ne s'agit plus seulement d'apprendre à quitter ses parents et à endosser l'habitus clérical ou congréganiste, il s'agit d'apprendre à 
mourir. En effet, dans les travaux des élèves, le développement d'un culte du sacrifice prend des proportions impressionnantes. Enfermés pendant leur cursus, le petit séminariste et a fortiori le petit scolastique de Cellule ne s'évadent que par l'attrait de lointaines contrées promettant "idéalement " une vie de souffrances. Plus qu'un futur prêtre, il devient en quelque sorte un martyr potentiel. Comme le note un jeune missionnaire auvergnat contemporain des débuts de l'établissement :

«Le sacrifice du missionnaire est plus grand que celui du prêtre ; le missionnaire a mille occasions de souffrir que n'a pas le prêtre : il est seul, abandonné ; son dévouement reste inconnu ; il fait du bien à des sauvages qui, bien souvent, ne comprennent pas ce dévouement, et qui, plus d'une fois, lui donnent la mort. Le missionnaire se donne plus que le prêtre : le prêtre donne sa personne, sa science, son travail, sa prière ; le missionnaire donne tout cela, et de plus sa patrie, ses parents, ses amis, sa vie, son sang. " ${ }^{(7)}$ Après un rapide survol des mécanismes et des agents pourvoyeurs de vocations et quelques lignes sur la Règle de Saint-Sauveur, l'article se focalise sur l'univers que les élèves sont amenés à se créer (la terre, l'espace et le temps). Puis il s'intéresse à la construction d'un ciel de petit séminaire pour enfin étudier le lien cellulien destiné à perdurer éternellement.

\section{L'enfant pris dans un réseau sacerdotal et religieux}

Dès leur installation, les spiritains mettent en œuvre les moyens classiques pour attirer à eux les enfants, en s'adressant au clergé du diocèse afin d'activer le réseau sacerdotal et religieux. Ainsi voit-on, en novembre 1856, le directeur de l'œuvre prendre contact avec les ecclésiastiques, débuter de cordiales relations avec l'établissement de religieuses récemment fondé à Cellule, visiter quelques écoles primaires, " mines de vocations » potentielles. Dans les premiers mois, on s'essaye à débaucher des recrues éventuelles dans des communautés religieuses, tel ce jeune homme présenté par un curé voisin et "qui sort de chez les maristes [...] qui ont inutilement cherché à le retenir ». ${ }^{(8)}$ Les spiritains sont efficacement secondés par la Sœur Andraud qui, jusqu'à sa mort en 1866, envoie de nombreux enfants vers l'établissement. Les lettres de recommandations de la religieuse sont à cet égard révélatrices. Pour faire entrer ses petits protégés à l'école, à l'orphelinat ou au petit séminaire, tantôt
(6) Erving Goffman,

Asiles, études sur la condition sociale des malades mentaux et autres reclus, Paris, éditions de Minuit, 1968, et Charles Amourous, Alain Blanc, [dir.], Erving Goffman et les institutions totales,

Paris, L'Harmattan, 2001.

(7) L.-P. Grangeon (abbé), Jean Barrier missionnaire au Kouang-Si. Vie et lettres, ClermontFerrand, Librairie catholique M. Bellet et Fils, 1889 , p. 115.

(8) Lettre au Supérieur Général, 22 novembre 1856 (ACCSp, 2 G 10 $9 \mathrm{a} 1)$. 
(9) « Courte notice sur

M. l'abbé Dozat, sousdiacre de la congrégation du Saint-Esprit, mort [...] le 5 juin 1871 ", Semaine religieuse de Clermont, $\mathrm{n}^{\circ} 25,2$ décembre 1871 , p. 392-394.

(10) Notice biographique sur Joseph, Marie, Antoine, Elie Andraud congréganiste des Saints Anges élève de bème [...], [1865], (ACCSp, 2 G 10 2a3). Son frère, Albert, ne persévère pas. elle joue de son action de fondatrice, arguant de la bonne éducation chrétienne des enfants : "Je ne crois pas d'ailleurs mon révérend père que les élèves que je vous propose soient de nature à vous faire regretter la confiance que vous avez la bienveillance de leur accorder "; tantôt elle flatte les Pères en leur faisant quasiment toujours miroiter une vocation possible : en 1858, c'est « le jeune orphelin Jean-Marie qui sous les auspices de la Reine du Ciel vous est conduit afin de faire s'il plaît au Seigneur un bon frère de votre congrégation ou au moins un fervent chrétien »; quant à Joseph, "il est heureux de rentrer dans la maison du Seigneur, il est bon cultivateur, il ne veut pas se marier, je crois qu'il vous conviendra ». Elle présente ses envoyés comme de douces brebis : "Votre bienveillante bonté ouvre le séminaire de Saint-Sauveur à Michel, il entre avec d'autant plus de joie que son attente a été longue et pleine d'anxiété [...]. Je vous assure que Michel sera un élève studieux, pieux et docile » (1865) ; ou encore, comme en 1859, elle présente leurs parents comme de bons catholiques désireux d'avoir un prêtre dans la famille : " [Le père] est aussi bon chrétien et si le bon Dieu donne la vocation de missionnaire à son fils, il ne s'y opposera pas "; " J'ai la signature du père et de la mère de Basile, en blanc au dessus, afin que vous y écriviez votre formule de leur consentement pour que leur fils prenne la soutane, et soit un jour père de votre congrégation ». La visitandine se fait également l'avocate de certains parents ne pouvant pas supporter les poids morts, telle cette «bonne veuve " désirant confier « son fils âgé de 17 ans non comme postulant frère puisqu'il est un peu infirme d'une main ce qui ne l'empêche pas de travailler la terre, mais comme agrégé pour la vie » (1857), ou essaie de leur trouver en plus quelques travaux rémunérateurs : «Veuillez donc [...] donner pour quarante francs d'ouvrage au père du jeune homme, c'est vous qui ferez ses prix » (1865).

Très vite, les spiritains accueillent nombre de neveux de prêtres ou de religieuses, tel Jean qui « donne quelque espérance " (1864) ou ce jeune orphelin ayant commencé auprès de son oncle curé sa prime éducation sacerdotale, " là dans la vie du presbytère, il puisa de bonne heure l'attrait pour le sacerdoce et un dégoût profond pour le monde ". ${ }^{(9)}$ La visitandine envoie même deux de ses neveux. ${ }^{(10)}$ Les appuis diocésains arrivent très tôt, avec l'abbé Mercier, futur vicaire général du diocèse, en charge de l'œuvre de la Propagation de la Foi, qui se fait recruteur. À sa mort, un projet de notice nécro- 
logique célèbre « le bonheur qu'il avait à nous procurer des postulants soit pour le scolasticat, soit pour le noviciat des Frères ", et affirme que " son plus grand bonheur eut été de voir quelques-uns de ses parents s'enrôler sous la bannière du Saint Coeur de Marie. Ainsi fut-il très content lorsque son neveu Antoine lui demanda la permission d'entrer dans notre petit scolasticat au commencement de l'année 1860 ; il le loua de sa détermination et lui donna les moyens de sa persévérance que cet enfant n'a point suivi à son grand regret. " ${ }^{(11)} \mathrm{On}$ trouve même les neveux de spiritains, celui du Supérieur du Séminaire français de Rome, qui entre à Cellule en 1859 pour y mourir un an plus tard, ou le petit Eugène que ses parents envoient vers Saint-Sauveur à la suite du passage de son oncle spiritain sur la terre des aïeux. En 1872, les membres de familles sacerdotales représentent un peu plus de $20 \%$ des effectifs. ${ }^{(12)}$ Entre dynastie sacerdotale avunculaire et petits paysans appelés, le schéma de recrutement est assez classique. ${ }^{(13)}$ Échanges de bons procédés : le clergé local recourt aux spiritains pour assurer telle ou telle charge, on remplace un curé malade, les religieuses alentours les veulent pour confesseurs, etc. ${ }^{(14)}$

Quelques familles ont tendance à vouloir absolument " faire un prêtre ", ce qui cause quelques problèmes au jeune Joseph qui, ne supportant plus les pensums et pénitences qu'on lui impose, écrit à ses parents dans un style inimitable :

"Mon idée est prise. Je ne puis plus rester à Cellule, [...] ce n’est pas ma sphère, comme un poisson que vous mettriez dans du vin, pensez-vous qu'il pourrait vivre, il y serait tout de suite asphyxié. Quoique je ne connaisse pas précisément ma vocation, cela n'empêche pas de m’ennuyer énormément dans l'existence que je mène, et songez que si [...] pour vous satisfaire, j'entrais dans une vocation qui n'est pas la mienne, j'y serai peut être damné, et puis quand j'ai voulu apprendre le latin ai-je pensé à me faire prêtre non, aucunement, je n'y songeais point, et ce n'est point à cause de l'être que j'ai désiré l'apprendre. [...] Mais je ne veux m'engager aucunement et ne l'ai pas encore fait de faire un prêtre. Je n'en sais rien. En attendant je ne puis plus rester dans cette maison qui m'est chère, mais qui n'est pas faite pour moi. [...] venez donc me chercher le plus tôt possible sera le meilleur.»

On trouve trace des tergiversations ultérieures de Joseph dans sa correspon-

(11) Monsieur Mercier dans ses rapports avec les Pères du Saint-Esprit et l'euvre qu'il dirigent à Cellule, [1871], (ACCSp, 2 G 10 8a2).

(12) Bulletin général, tome IX, 1872-1874, p. 376.

(13) Voir le très beau travail de Patrick Cabanel, Les cadets de Dieu.

Vocations et migrations religieuses en Gévaudan, XVIIIème-XXème siècles, Paris, CNRS Editions, 1997 ; et Yannick Essertel, "Réseaux et vocations missionnaires dans le diocèse de Lyon de 1815 à 1962 ", Revue d'histoire ecclésiastique, vol. XC, $\mathrm{n}^{\circ} 1-2$, janvier-juin 1995 , p. $49-70$.

(14) Bulletin général, tome VII, 1869-1870, p. 90 : «De toutes parts on demande des Pères de la communauté." 
(15) Voir respectivement Lettre de 1878 et Lettre au R.P. Supérieur, 12 janvier 1883, (ACSSp, 2 G 10 2a2). Joseph finit par perdre la foi.

(16) Règlement du Petit Séminaire de SaintSauveur à Cellule (Puy-deDôme), Riom, imp. G. Leboyer, 1877, p. 53-54.

(17) Ibid., p. 23.

(18) Résolutions prises à l'occasion de la retraite des 29-30-3I octobre I876 pour l'année scolaire I876I877, (ACSSp, 2 G 10 2a2). Gaston s'enfuit en janvier 1877, trop bavard sans doute. dance avec le Père Supérieur :

"Mes incertitudes au sujet de ma vocation ecclésiastique redoublent de jour en jour [...]. Mes parents [...] seraient quasi fous de me voir embrasser une autre carrière, en dehors du sacerdoce. " ${ }^{(15)}$

Dès le départ, l'enfant entrant à Cellule possède donc un minimum de dispositions, jouit d'une recommandation ou de qualités qui peuvent faire espérer. De par son origine familiale et sa prime éducation, il est en quelque sorte prédisposé, socialement et religieusement programmé. Le règlement de l'établissement, publié vingt ans après l'installation, insiste d'ailleurs sur le rôle des parents et sur leur adhésion au projet éducatif :

"L'action des familles n'est profitable pour le bien des enfants qu'à une condition, c'est que les parents s'identifieront avec la règle de la Maison, soutiendront toujours l'autorité, et ne demanderont pour leurs chers enfants aucune exception à la règle commune. On ne saurait croire combien ce respect pour la règle hautement professé par les familles a d'influence sur la formation des enfants. Sans ce respect, le parloir devient la ruine de l'action du Directeur. " ${ }^{(16)}$

Les enfants sont pour ainsi dire déjà prêts à l'emploi. Le terreau est fertile, les spiritains le cultivent.

\section{Celluliens par la Règle et par le ventre}

Devenir petit séminariste, c'est éprouver sa vocation supposée en se frottant à un règlement. Il ne paraît pas utile d'insister sur celui de l'établissement de Saint-Sauveur tant il paraît classique. Tout au long de l'année, du lever au coucher de l'élève tout est codifié :

"Au premier son de la cloche, les enfants sont éveillés par le surveillant du dortoir, qui les excite en disant à haute voix : benedicamus domino. Tous répondent : deo gratias. On ajoute : laudetur Jesus Christus, et chacun reprend : in aeternum amen. À ce signal, [...] les Petits Séminaristes se lèvent avec la généreuse promptitude du jeune Samuel répondant à l'appel de Dieu. Offrir à Notre Seigneur sa première pensée, par une élévation de l'âme vers lui ; sa première parole par l'invocation des saints noms de Jésus Marie Joseph ; son premier acte par un pieux signe de croix est la pratique journalière d'un enfant chrétien. " ${ }^{(17)}$ 
Comme toute production de ce type, ce règlement est tout autant un discours à destination des élèves et de leurs familles qu'un discours de la congrégation sur elle-même. Très classiquement, on y retrouve l'obéissance aux professeurs et aux Pères et une forte insistance sur l'amour de la Règle, tout ceci préparant doucement à l'intériorisation d'un ethos et à un exis sacerdotal. Règlement que de l'aveu de certains petits séminaristes il est parfois difficile de respecter, tel le jeune Gaston qui, lors d'une retraite, trahit malgré lui son peu d'appétence pour être un élève modèle :

"J'ai pris la résolution de persister dans le travail, de ne pas parler dans les rangs, au dortoir, au réfectoire, à la chapelle, dans les couloirs. De communier tous les dimanches. De dire un Memorare avant de me coucher. De commencer le jour qui commence par une courte prière. De ne dire aucune parole qui puisse blesser la charité ou la modestie. De faire mon possible à observer le règlement. " ${ }^{(18)}$

Citations et exemples bibliques à l'appui, l'une des images les plus classiques est celle du jeune Samuel, consacré dès sa naissance à Dieu par sa mère et ensuite appelé par Lui (1 Sm 1.28 sq.) ; il s'agit bien de modeler l'enfant, de favoriser sa vocation, de l'éduquer ${ }^{(19)}$ et de lui inculquer la fameuse modestie ecclésiastique. Ainsi lutte-t-on dès les débuts de la fondation contre le tutoiement dont la quasi-disparition, non sans efforts semble-t-il, est attribuée à la dévotion au Sacré Cour. ${ }^{(20)}$ Si l'on s'inquiète du régime alimentaire des élèves, c'est bien pour leur santé, mais c'est également parce qu'il peut être trop difficile à supporter et risque de porter atteinte à la culture des vocations. En 1863, un Père s'alarme et souhaite que les rations soient augmentées ; une nourriture trop chiche tend à faire regretter aux élèves la table familiale :

" [Les élèves] regrettent la maison paternelle en grande partie parce qu'ils ne peuvent se rassasier ici comme chez eux. Ce qui les fait soupirer après les sorties le premier jeudi du mois, c'est parce qu'ils pourront aller chez eux manger et boire. Mais ce qui est encore plus malheureux c'est que beaucoup de parents donnent dans le sens de leurs enfants et regrettent sincèrement que les enfants ne soient pas mieux nourris. " ${ }^{(21)}$

Pour ne pas achopper sur un tel sujet, on augmente les rations. Apprendre à préparer son corps et à le vaincre n'est pas si facile : "Nos jeunes aspirants
(19) Initialement,

les spiritains reconnaissent que l'enseignement est assez médiocre. Sur ce point, voir Claude Langlois, « Le temps des séminaristes. La formation cléricale en France aux XIXème et XXème siècles ", Problèmes d'histoire de l'éducation, Actes des séminaires organisés par l'École française de Rome et l'Università di Roma-La Sapienza, RomaParis, 1988, p. 229-255.

(20) Le Myosotis, n 21, 1er novembre 1879 , p. 8 : " $[\ldots]$ ce sera un ennemi de moins à combattre, au Grand séminaire!»

(21) Note au Révérend Père Supérieur sur le régime alimentaire de SaintSauveur, 11 août 1863, (ACSSp, 2 G 10 8a2). 
(22) Note relative aux scolastiques douteux pour défaut de santé, 6 juillet 1881, (ACSSp, 2 G10 1a4).

(23) Lettre du 27 janvier I858, (ACSSp, 2 G 10 9a2).

(24) En 1903, lors des mesures interdisant à la Congrégation de former des prêtres diocésains, l'évêque de Clermont reconnaît le bien-fondé d'une technique « aussi féconde et salutaire " pour « nos jeunes lévites » que pour les "futurs apôtres ", in « Lettre de Mgr l'évêque au R.P. Supérieur du Petit-Séminaire de Saint-Sauveur à Cellule ", Semaine religieuse de Clermont, $\mathrm{n}^{\circ} 37,12$ septembre 1903, p. 726. sont traités sérieusement et comme de grands religieux à une époque de la vie où la nature cherche sans cesse à prendre son expansion. Il y a donc de leur part et surtout chez les caractères les plus vifs, un effort de compression qui use la santé. Et ceci n'est pas particulier à notre ouvre $[\ldots] »,{ }^{(22)}$ remarquent les professeurs. On aurait tort de voir dans les spiritains de simples pères fouettards ne pensant qu'à usiner du futur missionnaire, ou d'insensibles ecclésiastiques obsédés par l'augmentation de leur taux de réussite. Les maladies et la mort des élèves ne les laissent pas de marbre, comme en témoigne une lettre datant des premières années de l'établissement, où le directeur, parlant du jeune Antoine se démenant contre une pneumonie « avec son chapelet, son scapulaire et une petite image de la Sainte Vierge ", avoue que sa missive n'est " qu'un cri de détresse ». (23) À peine rétabli, Antoine écrit à son tour une lettre au Supérieur pour le remercier de sa "sainte bénédiction qui [lui] a beaucoup réjoui le cour, qui [l’] a beaucoup fortifié et soulagé "; il raconte que, pendant sa maladie, il n'a « cessé de prier la Sainte Vierge pour qu' elle [le] fasse devenir [prêtre] dans la congrégation ».

\section{La terre, l'espace et le temps}

Bien plus que le règlement, les travaux et lettres des élèves, les résolutions qu'ils prennent à la fin des retraites, les comptes rendus qu'ils font de leurs actions paraissent peut-être plus intéressants pour saisir l'intériorisation d'un habitus sacerdotal et missionnaire. Par-delà les exercices de piété, l'uniforme un paletot noir - et l'extrême régularité de la vie cellulienne, les productions des élèves renseignent de manière plus fine sur les processus visant à faire d'eux de futurs bons prêtres, voire des athlètes de Jésus-Christ pour filer une métaphore paulinienne. On n'est pas petit séminariste seulement parce que l'on suit un règlement corps et âme, on le devient également par l'encre et la plume, par la façon de mettre en scène ses activités dans l'espace et le temps.

Les spiritains favorisent la concurrence entre petits séminaristes et petits scolastiques, c'est à qui sera le plus pieux ou le plus studieux. ${ }^{(24)}$ Pour encourager l'émulation interne, pour amener doucement l'élève à avoir un comportement de futur lévite, on érige, comme dans bien d'autres établissements, diverses congrégations : celle des Enfants de Marie (1861) qui rassemble les meilleurs éléments, celle de Notre-Dame des Anges pour les plus jeunes ou 
l'œuvre de Notre-Dame de la Vocation (1878). ${ }^{(25)}$ On fonde également, en 1862, l'Académie du Saint et Immaculé Cour de Marie, "dans le but de répandre dans les classes une louable émulation, [...] composée des élèves qui se font remarquer tant par leur bon esprit que par leurs talents ». Ainsi encourage-t-on la concurrence en séparant les "meilleurs". Les membres de ces pieuses associations se rassemblent pour leurs propres activités, et les élèves en rendent compte dans La Semaine de Saint-Sauveur, bulletin intérieur de l'établissement créé en 1861, à l'instar de ce récit d'intégration de nouveaux Enfants de Marie :

«Suivons ces jeunes élèves se dirigeant vers le sanctuaire, la joie brille sur leurs fronts, ils sont modestes et silencieux, des médailles [...] brillent sur leurs poitrines, déjà ils sont au pied des autels, leurs regards s'animent en voyant l'image de la Reine du ciel placée sur un trône resplendissant. [...] Et pleins de joie, ils s'avancent et reçoivent la médaille qui doit leur rappeler leurs engagements et se précipitent dans les bras de leurs jeunes frères en Marie. Ceux-ci les pressent tendrement sur leur cœur et leurs regards expriment le bonheur qu'eux-mêmes éprouvent de voir de nouveaux frères grossir les rangs de la petite famille de Marie. " (26)

Description compassée de la joie des impétrants se mêlant à celle des anciens, image de l'entrée en une communauté nouvelle, quasi-répétition d'une ordination sacerdotale.

Les petits scolastiques, éventuels futurs spiritains, doivent également se mettre en relation avec les grands scolastiques partis poursuivre leur formation à Paris. Chaque trimestre un petit est " chargé " d'écrire aux grands. L'exercice ne semble pas facile, puisqu'il faut trouver quelque chose à raconter. De nombreuses lettres trahissent la vie monotone : "J'ai beau regarder de tous les côtés dans l'espoir de vous faire part de quelques nouvelles intéressantes mais je ne trouve absolument rien » (février 1863) ; « les nouvelles ne sont pas abondantes mais en cherchant un peu je parviendrai peut-être à en mettre quelques-unes sur ce papier " (septembre 1872). La répétition est condition sine qua non de tout projet congréganiste :

«Ainsi se passent les jours, les semaines et les mois, dans la répétition d'exercices journaliers, dont on apprécie moins le prix, à cause de la facilité méritoire qu'on a contractée à les remplir. De temps en temps viennent de grands

(25) Voir Mémorial des enfants de Marie du Petit Séminaire de SaintSauveur à Cellule, Riom, imp. G. Leboyer, 1868, 124 p. ; Euvre de NotreDame de la vocation,

Riom, impr. G. Leboyer, 1878, 15 p.

(26) Barthélémy, petit séminariste, élève de seconde, "Fête de Saint Stanislas Kotska », $L a$ Semaine de Saint-Sauveur, $\mathrm{n}^{\circ} 1$, samedi 16 novembre 1861. Kotska (1550-1568, canonisé en 1726),

passant outre l'opposition paternelle, s'enfuit de chez lui pour entrer chez les Jésuites. Le choix d'un tel jour n'est pas anodin. Le petit Barthélémy devint prêtre diocésain.

(27) «Biographie de Joseph Davignon, en religion Marie, petit scolastique de la congrégation mort le 19 juillet 1863 ", Le Myosotis, suppl. au n ${ }^{\circ} 40$, 1er août 1884, p. 521. Le texte date de 1864. 
(28) Blaise grandit et entre dans la Congrégation, après une longue carrière d'enseignant en France et en Haïti, il s'éteint « doucement " à Cellule en octobre 1927. Voir «Nécrologie : Blaise Pallier ", Bulletin général, tome XXXIII, 1927. Voir p. 418-421.

(29) Lettre d'un petit scolastique aux grands scolastiques, janvier 1863 (ACSSp, 2 G 10 2a1).

(30) Petit scolasticat. Notes de I860 à I 880 , (ACSSp, 2 G 10 3b1).

(31) La semaine de Saint-Sauveur, $\mathrm{n}^{\circ} 5$, 14 décembre 1861, n.p. L'oblation est le premier temps de consécration des aspirants scolastiques, elle differe de la profession beaucoup plus tardive.

(32) M. Tacheix, élève de seconde, « La première visite du TRP Emonet, jours qui, en rompant l'uniformité, ne font qu'exciter plus vivement l'amour. Ce sont de belles fêtes qui développent la piété dans les cœurs. " ${ }^{(27)}$ Outre son caractère obligatoire, cet exercice de « lettres aux Grands » incline l'élève à se projeter dans l'avenir, comme le note le jeune Blaise Pallier :

"Nous commençons à mener en petit la vie que vous menez vous-mêmes dans votre grand scolasticat, nous ne pouvons pas l'observer en grand puisque nous sommes petits."

Dans cette logique implacable, le jeune scolastique se place sur un continuum, petit il s'entraîne à devenir grand et partira lui aussi faire comme ses aînés. ${ }^{(28)}$ Répétitions là encore. À Cellule, on passe son temps à essayer de devenir grand. Cette thématique de l'entraînement est explicitement évoquée par les jeunes :

"Nous nous aguerr[iss] ons ensemble, pour commencer un jour la lutte universelle contre l'empire du démon, et nos coeurs demeurent unis pour toujours dans le cœur immaculé de Marie, sans que ni la distance des lieux, ni l'immensité des mers ne puissent jamais les séparer. Voilà certes un heureux avenir qui, de plus, sera couronné par une éternelle félicité. " (29)

Le temps de Cellule est un temps sacerdotal, un temps de congrégation, et pour l'élève et ses maîtres un temps de discernement de sa vocation à l'instar des petits scolastiques qui sont évalués sous plusieurs angles ("Santé, Capacités, Travail, Caractère, Éducation, Conduite, Piété, Amour pour la Congrégation »). ${ }^{(30)}$ Le temps cellulien se répète, il s'inculque. La monotonie n'est rompue que par des moments forts, tous religieux, et notamment par les prises d'habits lors d'oblations de petits scolastiques, premiers pas dans la Congrégation, dont les élèves rendent compte :

« Un grand acte va s'accomplir, un acte qui exciterait le sourire des orgueilleux enfants du siècle, mais qui réjouira Dieu et la cour céleste. Ces deux chrétiens que nous voyons abîmés dans la méditation vont prononcer leurs adieux au monde en se dépouillant de ses livrées. "(31)

Certaines cérémonies exceptionnelles peuvent d'ailleurs s'étaler sur plusieurs jours à l'image de la visite du Supérieur Général pour laquelle Pères et élèves se démènent et dont le programme est révélateur de l'aspiration missionnaire régnant dans l'établissement. ${ }^{(32)}$

Dans leurs travaux, les élèves se placent symboliquement dans un intem- 
porel catholique remontant aux sources de leur foi ; les comparaisons avec les premières communautés chrétiennes sont légions, les thématiques bibliques lourdement présentes. Par-delà les exercices imposés et les références plus ou moins bien digérées, les élèves sont invités à raconter ce que devrait être leur avenir. Eux aussi seront tôt ou tard appelés à se détourner du monde pour répondre à l'appel, comme le dit à chaque événement d'importance le supérieur de la communauté, dans ces "petites allocutions [qui ont] fortifié plus d'une vocation naissante parmi les Petits Séminaristes ». ${ }^{(33)}$ Tous ces exercices ont une finalité, précise et affichée : fortifier leur éventuelle vocation et trier le bon grain de l'ivraie. Les spiritains annoncent d'ailleurs clairement que leur établissement peut recevoir des élèves ne se destinant pas au sacerdoce, mais souhaitant recevoir une " éducation chrétienne ». L'image du jeune Enfant de Marie au pied des autels ou celle du prêtre contemplant « le divin prisonnier du Tabernacle " jalonne les travaux. Physiquement, spirituellement, symboliquement et par la plume, l'enfant, dans ses exercices, est mis en position de répondre à l'appel ou pour le moins de s'interroger sur ce thème. On est audelà de l'assistance journalière à l'eucharistie auquel tout petit séminariste se doit d'assister. Pour preuve, ces sermons et autres exercices rédigés par les élèves académiciens, où l'on peut voir Eugène, Pierre, Eugène-François, Louis et Stéphane plancher en prose ou en vers, en français ou en latin, sur la thématique du jeune prêtre abîmé en contemplation, faisant part de ses doutes et hésitations pour remplir la tâche qui lui est assignée et à qui le Christ vient parler. Comme on s'en doute, à la fin, le jeune prêtre, rassuré et fortifié "par l'entretien céleste ", continue de gravir les degrés de l'autel. ${ }^{\left({ }^{34)}\right.}$

Petits séminaristes et petits scolastiques, en narrant dans leur journal ou à leurs anciens les diverses cérémonies extraordinaires auxquelles ils assistent, se mettent en position de se poser la question du " pourquoi pas nous ", ce que les spiritains n'ont de cesse de rappeler lors d'occasions solennelles, telle cette prise d'habits de 1877 :

"Pour vous chers enfants, [...] cette cérémonie instructive et touchante [...] doit d'abord vous faire admirer et adorer les desseins de Dieu qui vous a mis en relation avec des condisciples généreux appelés par Lui [...] pour être consacrés à Lui sous vos yeux : ils sont ce que vous êtes, et déjà la voix du Très-Haut s'est fait entendre à eux comme autrefois au jeune Samuel.
Supérieur Général de la

Congrégation $[. .$.$] ,$

27 juin-1er juillet ", Le

Myosotis, $\mathrm{n}^{\circ} 36$, 1er août

1883 p. 391-398.

Le programme du 29 juin, de la « Petite prière pour les noirs " d'un élève

de 7ème, en passant par la version latine d'un élève de 5 ème concernant « Le modèle du Missionnaire tracé par Saint Augustin ", jusqu'aux discours sur

"Les qualités du Missionnaire " par un petit scolastique rhétoricien, trahit l'ambiance africaine.

(33) In Lettre d'un petit scolastique aux grands scolastiques, 21 mars 1861, (ACCSp, 2 G 10 2a1).

(34) Voir Tibi Cor Jesu Sacratissimum, nos secundani, pia devotione incitati, opera in honorem Tuum suscepta, dicamus.

Die XI februarii anni MDCCCLXXX, (ACCSp, 2 G $107 b)$. 
(35) Le Myosotis,

$\mathrm{n}^{\circ} 13,1$ er novembre 1877 , p. 277.

(36) In Compte rendu

du second semestre et de toute l'année scolaire et religieuse, août 1870 ,

(ACCSp, 2 G 10 3b1).

Le thème est récurrent et argumenté, citations bibliques à l'appui $(\mathrm{Mt}$ 10.37 et Ac 5.29) : mieux vaut obéir à Dieu qu'aux hommes et, pour en être digne, ne point lui préférer sa famille.

(37) Roy, élève de troisième, La messe de minuit au Petit séminaire de Saint-Sauveur, 25 décembre $1862:$ un ange gardien qui parle à un enfant, (ACCSp, 2 G 10 1a2).
Cette voix parle ou parlera aussi à chacun de vous, car il n'est personne qu'elle oublie. Étudiez-vous pour ne pas l'étouffer, pour en saisir les accents et pour en suivre scrupuleusement la direction. Votre présence dans cette enceinte [...] est déjà une bénédiction de Dieu sur vous, un saint appel de sa miséricorde : vivez ici en parfait séminariste, en luttant contre votre légèreté et en étant fidèles au règlement, et vous êtes sûrs que vous entendrez, à un moment donné, ce que Dieu vous dira pour l'avenir. Vous suivrez alors la voie tracée par vos pieux devanciers et vous peuplerez les grands séminaires, d'où vous ne sortirez que les hérauts de la bonne nouvelle auprès des peuples. "(35)

Tout est donc en place pour préparer, le moment venu, l'élève à choisir et à entendre.

Se projeter dans l'avenir doit impérativement entraîner une rupture avec le passé et, en premier lieu, avec sa famille et son pays. Le temps cellulien est aussi celui du rejet, d'une certaine forme de contemptus mundi. On touche là un des points fondamentaux de l'inculcation de l'habitus sacerdotal et missionnaire. Comme toute institution cléricale, les Pères spiritains sont d'ailleurs bien conscients du problème. Au sujet des petits scolastiques, l'un d'entre eux note que " [ $l$ '] amour pour la congrégation a cependant pour plusieurs un ennemi : l'affection pour les parents ". ${ }^{(36)}$ Dès lors, dans les poèmes français ou latins qu'ils composent, dans les rédactions qu'ils exécutent, dans les dialogues qu'ils inventent, les petits séminaristes doivent sans cesse mettre en avant ce rejet du foyer et des parents. Ainsi ce dialogue entre l'ange gardien et l'enfant écrit par un élève, où l'ange explique à son protégé tout ce qu'on peut gagner en préférant Dieu à sa famille. La scène se passe juste avant la messe de minuit :

«[...] Oh bon ange je ne me sentirai pas le courage de quitter ma mère. / Aussi Jésus ne le demande-t-il point de tout le monde. Mais ceux à qui il le demande doivent obéir à la voix, sinon ils s'exposent grandement à ne jamais entrer dans le ciel [...]. Ils quittent tout, cher enfant, mais ils retrouvent aussi tout et cent fois plus en Jésus. Oh! si tu pouvais lire dans leurs cours combien ils sont heureux, tu n'aurais point envie de les plaindre [...] Lorsqu'ils seront prêtres, ils iront dans des contrées lointaines [...] parmi les païens et les sauvages leur prêcher la religion catholique. " ${ }^{(37)}$ 
Le petit séminariste se trouve placé dans un système de marchandage présacerdotal. Si, et seulement s'il est appelé et s'il se refuse, il n’ira pas au ciel retrouver un jour sa mère. S'il la quitte, il en retrouvera une autre en la personne de la Vierge. S'il laisse sa famille, il en retrouve une autre en ses collègues, lévites diocésains ou congréganistes. Dans les textes que produisent les élèves, l'appel se veut irrépressible, tel cet autre dialogue entre la voix et l'enfant qui affirme, tout en alexandrins :

«Ah ! j’ai quitté ma mère, et son dernier baiser / Est empreint sur mon front ; ma main froide et glacée / Dans la sienne est encore avec amour pressée. / De ses yeux fatigués je vois couler des pleurs / Qui ne peuvent, hélas ! adoucir ses douleurs. / Mais je monte vers Dieu, devant qui tout s'efface, / Et ma mère du ciel auprès de lui me place. / Dans ton immensité, je me perds... ô mon Dieu ! / Recevez votre enfant... Et vous, mortels, adieu ! "(38)

On a beau être issu d'une famille catholique, vivre dans un saint lieu, sur une terre chrétienne, il n'en faudra pas moins les quitter avec pour seul bagage la souffrance et le réconfort de La Mère : "O bonne mère / Du missionnaire / Vois tes enfants / Entends leurs chants / Sur la terre ils n'ont plus de patrie / La croix leur reste et toi Marie ", écrit un petit scolastique. ${ }^{(39)}$ Répétitions ou préludes au fameux "Chant du départ " que le petit scolastique, devenu grand et Père spiritain, entonne avec ses homologues à la veille de partir pour la mission et que l'on trouve, fort logiquement, dans Le Myosotis, bulletin de Saint-Sauveur. Dans ce chant où les missionnaires, "soldats du Christ ", se préparent à partir, prêts à souffrir (" et s’il le faut allons mourir ! »), le deuxième couplet traduit bien cet abandon de la famille ( Amis pourquoi cette larme qui tombe? / parents chrétiens, que nous demandez-vous ? / Loin du berceau nous creusons notre tombe ; / mais Dieu le veut, mais Chanaan succombe : / au ciel, au ciel le rendez-vous !»), et le troisième l'image d'une Vierge Maris Stella, seule consolatrice (" Astre des mers si l'Apôtre t'implore, / guide-le bien : il porte le Sauveur... / Ô Vierge, ô Mère, ô souriante Aurore, / À qui perd tout tu resteras encore, / et tu suffis pour le bonheur ! "( $\left.{ }^{(40)}\right)$. Toute l'éducation du petit scolastique prépare à ce moment.

On a là un thème récurrent qui agite la littérature missionnaire jusqu'à Vatican II. Prenons juste l'exemple d'une brochure spiritaine éditée dans les années 1930, Missionnaire... Pourquoi pas ?, qui reprend la thématique par le
(38) « Dialogue : La voix et l'enfant (1863)", Souvenirs de Saint-Sauveur ou essais littéraires des élèves du Petit Séminaire de Cellule, Paris, Bray et Retaux, s.d., [1872], p. 44.

(39) Cantique composé par un petit scolastique (ACCSp, 2 G 10 2a2), la suite est de la même veine : "Sous ta tutelle / Vierge fidèle / On est heureux / On tend aux cieux / Protège nous toute la vie / Nous sommes tiens Vierge Marie. "

(40) Le Myosotis, $\mathrm{n}^{\circ} 26$, 1 er février 1881 , p. $156-$ 157. Ce cantique est entonné juste après la formule de consécration lors de l'ordination ; voir Georges Goyau, Clergé colonial et spiritualité missionnaire. La congrégation du Saint-Esprit, Paris, Grasset, 1937, p. 228 sq. Sur ce texte, chanté jusque dans les années 1950 , voir Alexandre Le Roy, « La spiritualité mission- 
naire spiritaine à travers la

Prière de consécration à

l'apostolat et le Chant du

départ ", Mémoire

spiritaine, $\mathrm{n}^{\circ} 16$, deuxième

semestre 2002,

p. $135-142$.

(41) Missionnaire...

Pourquoi pas ?, Paris,

Maison-Mère des Pères du

St-Esprit, 1939, p. 30 et

37. En 1946, dans le diocèse voisin du Puy,

L. Barjon et A. Rétif

publient Le missionnaire,

Le Puy, X. Mappus Édi-

teur, 1946, 371 p., dans

une collection intitulée

« Nos beaux métiers par

les textes" $(s i c)$. On a

là un exemple paradigma-

tique de productions

catholiques de diocèses de chrétienté, où partir pour

la Mission est assimilé à

une occupation (presque)

comme une autre. biais d'une lettre d'un missionnaire "camerounais" à un enfant, en abordant la mort prochaine de la mère restée en France, apprise peu avant le baptême de catéchumènes.

« Le matin, j'avais le bras sans force pour verser l'eau sainte. D'abord je tremblai comme un demi-paralytique. Puis il me sembla que quelqu'un affermissait peu à peu mes muscles. C'était comme si l'absente était venue baptiser avec moi. [...] elle m'inspire en chaire et au confessionnal, sa maladie me communique la fièvre dont on ne peut ni guérir ni mourir. [...] Dès lors, bien que je ne pusse me défendre d'une perpétuelle anxiété, ma vocation ne cessa de grandir."

On a ici une démonstration se voulant éclatante ; même absente, même mourante, la mère est là... C'est dans l'épreuve que grandit la vocation et que l'on se grandit. Et le texte de continuer sur les "déchirements " liés à la vie missionnaire, avec des images accessibles à tout petit catholique de l'époque ( Job a été plus frappé par la perte des siens que par les plaies de son corps »), pour chercher le repos "en Dieu, en lui criant les trois premières évocations du Pater", trouver " la paix, qui n'est pas celle que le monde donne " et s'achever «dans la parole du Christ : Quiconque perdra sa vie à cause de moi la trouvera ». ${ }^{(41)}$ À Cellule, comme plus tard au Cameroun, symboliquement, la mère et la famille ne sont plus vraiment des problèmes, ni même des écueils dans la vocation. En témoigne un texte de 1882, dans lequel les petits celluliens rendent compte d'un sermon fait par leur professeur de Seconde lors de leur pèlerinage annuel à la cathédrale de Clermont-Ferrand. Les petits séminaristes insistent sur la radicalité de l'appel et sur le pourquoi de leur venue à Saint-Sauveur. Ce ne sont plus les parents qui les ont amenés à Cellule, c'est tout simplement la Vierge :

«Marie vous a fait Séminaristes [...] Marie vous fera prêtres. [...] Rendezvous dignes de pareille grandeur par votre science, vos vertus et surtout par votre esprit de foi, en pesant tout au poids du sanctuaire [...]. Mais quelle est cette nef gracieuse, qui vogue sur l'océan comme une colline de fleurs ! [...] sur le tillac se tient une femme entourée d'étoiles, elle dirige le gouvernail et sur son front est écrit : Notre-Dame de la Vocation. Rangés autour d'elle, les passagers célèbrent le bonheur d'appartenir à Marie, et promettent de rester dignes de leur Mère [...]. Cette nef est ce sanctuaire, et ses 
passagers c'est vous. [...] Et s'il faut que les uns après les autres [l]es passagers [...] s'en aillent se briser contre l'écueil, où toute chose se brise, oh ! n'ayez pas peur, chers enfants, vous ne tomberez pas dans l'abîme, vous tomberez, mais dans les bras de Marie. " ${ }^{(42)}$

Que peuvent faire ou dire les mères face à l'appel de La Mère ? Rien. Que peuvent faire ou dire les enfants face à Leur Mère ? Suivre son appel.

Ce type de discours et d'images assez communes, sans cesse répétés, semblent marquer profondément les élèves, à l'instar du jeune Toussaint qui, dans une lettre au Supérieur, reprend des images similaires :

«Rendons grâces à Dieu et à Notre-Dame de la Vocation. [...] en sortant de ma vocation, qu'allais-je devenir ? J'étais un navire démâté, abandonné à la fureur des flots... et voici que l'étoile de la mer a dissipé les ténèbres et l'orage. Et Dieu, dont le cœur renferme des trésors incompréhensibles de miséricorde et d'amour, m’a pris par la main et m'a ramené dans la bonne voie. " ${ }^{(43)}$

Dans un lieu béni, on est à l'image des premières communautés chrétiennes, sur une terre catholique, dans cette Auvergne des pères qui continue de fabriquer des petits missionnaires et qu'on loue à n'en plus finir : "L'énergie, le dévouement, le zèle, la foi, la fidélité, ne sont-ce pas les traits d'un véritable auvergnat ? ", se demande-t-on. ${ }^{(44)}$ En effet, si le temps est catholique, l'espace dans lequel sont insérés petits séminaristes et scolastiques l'est également. Espace de l'établissement qui s'agrandit et s'embellit en s'ornant de chapelles, de statues de Notre-Dame. Espace des paroisses environnantes fertile en vocations, " preuve vivante de ce que peut la foi dans un pays, lorsqu'elle se trouve encouragée et secondée par les moyens que la Providence met à sa portée. Là aussi le Seigneur a destiné certaines familles comme devant donner à l'Église des prêtres et des apôtres. Il a voulu les glorifier dans leurs enfants, en choisissant ceux-ci pour ses instruments dans l'évangélisation des peuplades lointaines ". ${ }^{(45)}$ Comme l'affirme un abbé historien, c'est avant tout aux Pères du Saint-Esprit et aux élèves de Saint-Sauveur qu'on doit cette mise en catholicité de l'espace cellulien : "Aujourd'hui, en considérant l'histoire de cet obscur village, on est obligé de reconnaître que son passé, quelque beau qu'il soit, n'est cependant pas comparable à son présent. " ${ }^{(46)}$ On le voit, avant l'établissement de Saint-Sauveur il n'y avait rien, depuis sa fondation il y a
(42) Le Myosotis, $\mathrm{n}^{\circ} 33$, 1er novembre 1882 , p. 316

(43) Lettre de Toussaint Vivier, 21 mai 1878, (ACSSp, 2 G 10 2a1).

(44) « Courte biographie sur le Révérend Père Jean Blanzat s. sp. c. i. m. mort à Pondichéry le 14 mai 1884 ", Le Myosotis, $\mathrm{n}^{\circ} 46$, 1er février 1886. Le cellulien est mort à 24 ans.

(45) J. Wiisler, scolastique, ancien élève de [la classe de] Rhétorique, "Les celluliens missionnaires des noirs ", $L e$ Myosotis, n 23 , 1er mai 1880 , p. 70.

(46) Notice historique sur la paroisse de Cellule, Riom, imp. G. Leboyer, 1870 , p. 56. 
(47) Rapport de

l'Inspecteur d'Académie au Préfet du Puy-de-Dôme,

7 septembre 1868

(ADPdD, 6V7). tout ou presque : de bons chrétiens, de futurs prêtres et d'éventuels missionnaires. Même le pouvoir impérial se félicite du travail entrepris, louant les " utiles services » rendus par les Pères. ${ }^{(47)}$

Préparer sa vocation ne requiert pas seulement plume, encre et abstinence. Ce n'est pas uniquement cultiver les joies du latin et porter des médailles d'enfants de Marie. Par l'évocation de la mort et des martyrs, le petit séminariste combat pour Dieu et doit se préparer à mourir pour Lui.

\section{La mort et le ciel : la mise en place de l'Au-delà cellulien}

C'est par la mort de leurs petits camarades ou de leurs professeurs que les petits séminaristes et petits scolastiques sont amenés à côtoyer et à connaître (le sens de) leur sacrifice de manière moins idéelle que dans leurs livres et exercices rhétoriques. Bien souvent, ce sont les élèves qui rédigent les notices nécrologiques de leurs condisciples, mettant en lignes et en mots l'arsenal de références dont ils sont nourris, faisant des défunts des modèles à suivre, les parant de toutes les qualités du cellulien modèle, du chrétien fervent et surtout de celles du futur prêtre ou du futur missionnaire, " amoureux » jusqu’à son dernier souffle de sa congrégation. Les petits disparus vont ainsi participer de la légende dorée de Saint-Sauveur. Au fil des ans et des pages, le ciel tend à devenir cellulien. Le modèle n'est plus seulement chez les saints ou chez les Pères enseignants, mais juste à côté de soi, plus proche et d'une certaine façon moins virtuel. Si le Christ est finalement assez loin, le condisciple avec lequel on a partagé un moment de sa vie est, lui, accessible.

Prenons juste quelques exemples de ces morts mises en scène par les élèves, telle celle du jeune Jean Brumerol, admis à l'orphelinat, retourné ad Patres à dix huit ans, dont le jeune rédacteur rappelle la pieuse mère, son " ardent désir d'entrer dans la Congrégation ", désir comme il se doit contrarié par sa " difformité ", dont on loue l'obéissance. Jean souffrant de phtisie et se trầnant jusqu'à la chapelle, ne craignant pas de mourir, n'ayant rien à dire à sa famille au seuil de son trépas et qui, à l'approche des derniers sacrements, souhaite entrer dans la congrégation des Enfants de Marie. Mort tournée vers La Mère, dans la communauté, avec chapelet dans son cercueil. Toutes ces étapes et images imposées sont très classiques sous la plume d'un curé ; sous celle d'un enfant de quatorze ans, elles le sont peut-être moins... 
On souffre et l'on meurt pieusement ; l'odeur de sainteté n'est pas bien loin avec le jeune Saturnin Coutarel, mort à 13 ans en 1860, neveu de curé et petit protégé de la Sour Marie Emmanuel, « jeune prédestiné » désirant être prêtre, refusant de se plier aux objurgations des siens : "Il a été inébranlable, sa résolution était fixe : il voulait être prêtre. » Le rédacteur ajoute que " son attachement pour la société apparaissait jusque dans sa manière d'être et de dire. Il s'identifiait tellement avec nous qu'il agissait et parlait comme si déjà il eût été membre de la Congrégation ». Ce type d'assertion marque à la fois la volonté d'édification de l'élève lecteur et amplifie la réussite du mécanisme d'inculcation missionnaire. Saturnin est alors paré de tous les traits du bon congréganiste qu'il n'a pu être. Il est fidèle à l'œuvre et à ses supérieurs ("Il voyait dans ses supérieurs les représentants de Dieu lui-même ", banale thématique de toute constitution religieuse) ; on loue son « ardeur incroyable pour s'avancer dans la perfection, saisissa[nt] jusqu'aux moindres circonstances pour y faire un pas de plus ». L'élève biographe évoque sa tenue simple et modeste et donne à méditer ses résolutions :

" Je ne suis encore que postulant, et je commence à me former pour entrer un jour dans la congrégation du Saint-Esprit et du Saint Coeur de Marie, pour le service de Dieu, pour marcher dans le chemin du ciel et pour être un bon missionnaire de cette congrégation [...] Oh ! Si j'avais le bonheur d'aller prêcher la mission en Afrique!"

Enfin il ajoute que, pendant sa maladie, Saturnin « ne parla pas une seule fois de ses parents auxquels on eut dit qu'il avait déjà totalement renoncé ". La boucle est bouclée, le jeune rédacteur place dans le ciel un enfant déjà presque spiritain. On peut se demander, au travers de cette nécrologie, si les enfants ne deviennent pas d'une certaine façon des modèles pour leurs éducateurs. On peut se demander également si les spiritains ne verraient pas d'un bon œil la récente fondation de Cellule rafraîchie par une odeur de sainteté, comme il est de coutume dans de nombreuses congrégations ou établissements en période de fondation et d'affermissement. Histoire d'avoir plus d'éclat dans le ciel et sur terre à une époque et dans une région où la quête du saint est chose assez commune. ${ }^{(48)}$ Autre exemple, plus réellement missionnaire celui-là, le jeune Ernest, guyanais né esclave à Cayenne en 1845, " de cette race si malheureuse que des hommes inhumains réduisaient à une
(48) Voir, par exemple, Jacques Gélis, «Les miracles du "bon Père Gaschon" ", in JeanClaude Schmitt, [dir.], Les Saints et les Stars. Le texte hagiographique dans la culture populaire, Paris, Beauchesne, 1983, p. 197-221. François Gaschon œuvre à Ambert et meurt en 1815 ; tout au long du siècle, on cherche à faire un saint de celui qui, comme modèle du prêtre, concurrence un moment le curé d'Ars. 
(49) Sur ces trois jeunes défunts, voir : Michel, élève de Rhétorique,

"Notice sur Jean Brumerol décédé à l'âge de 18 ans à l'orphelinat de Saint-Sauveur le 4 janvier 1862 », La semaine de Saint-Sauveur, n ${ }^{\circ}$ 9, 11 janvier 1862 ; Notice biographique sur Saturnin Coutarel aspirant petit scolastique de SaintSauveur mort à Cellule, en odeur de sainteté, le six août I860, dans sa treizième année [1860] ; et Notice biographique sur Ernest Polycarpe, petit scolastique de la congrégation $d u$ Saint-Esprit et du Saint Cour de Marie, mort à la Mission de Dakar, le 28 mars I865 [1865], (ACSSp, 2 G $102 a 3)$. Vingt ans plus tard, ces notices sont exhumées et publiées dans les colonnes du bulletin cellulien (voir Le Myosotis, $n^{\circ} 22,1$ er février 1880 ; $\mathrm{n}^{\circ} 17$, 1er novembre 1879 ; $n^{\circ} 32$, 1er août 1882). dure servitude ", protégé de la Sœur Marie Emmanuel et mort en Afrique à même pas vingt ans. ${ }^{(49)}$

Tels sont les modèles qu'on donne aux enfants et qu'ils se donnent à euxmêmes. Le schéma narratif est toujours identique : une mère pieuse ou morte, un oncle souvent curé, la volonté infaillible de l'enfant pour entrer dans la voie du sacerdoce, l'élève modèle, la tenue quasi-sacerdotale, la manière de supporter sans douleur les souffrances pour le petit séminariste, et pour les petits scolastiques, l'amour de la congrégation. Se dessine ainsi une galerie de saints enfants et de saints pour les enfants, mis en scène par les enfants. Les parfums de Saint-Sauveur ou la sainteté endogène et in vivo... Dès le plus jeune âge, le nécrologe devient un compagnon familier, préfigurant le martyrologe missionnaire.

Les orphelins de Cellule accompagnent Jean au cimetière, les petits séminaristes ont vécu dans les odeurs de sainteté de Saturnin, les petits scolastiques au contact d'Ernest, tous assisteront à la translation des restes du Frère Élie, "fondateur " de la communauté, qui, sous la plume du petit scolastique racontant cet épisode, devient un presque saint, un modèle. Sa nécrologie est archétypale. ${ }^{(50)}$ On fait du Frère Élie, né en pleine Révolution, une vocation contrariée, obligé de se marier, puis se retirant dans une église abandonnée qu’il transforme en ermitage. Le temps d'Élie, devenu tertiaire franciscain, " était partagé entre la prière et le travail à la manière des anciens solitaires ". Dieu lui fait trouver dans la congrégation du Saint-Esprit un pieux asile, où il pourrait, dans le recueillement et la prière, achever paisiblement le cours de ses jours. Et, en juin 1864 , on procède à la translation de ses restes du cimetière communal vers la chapelle du petit séminaire, événement pour lequel les élèves sont mobilisés et que les petits scolastiques s'empressent de raconter à leurs aînés :

«Le cadavre reposait tout entier sur la seule planche du fond. Toute chair avait disparu. [...] Le grand scapulaire bleu de la congrégation en fut tiré [...]. On trouva aussi des restes de chapelet et de chaîne de fer, ainsi que la corde que le bon Frère Élie portait comme Tertiaire de Saint François. Avant de fermer le cercueil, le Frère Ignace prit un morceau de chaîne et un scolastique détacha quelques cheveux pour les conserver comme reliques. Puis quatre frères portant les précieux restes se mirent au milieu des rangs et nous nous rendîmes à la Chapelle de la maison en psalmodiant [...]. 
Dès qu'on fut arrivé un coup de cloche réunit dans le lieu saint tout le reste de la communauté [...]. Le cercueil fut placé au milieu du chœur et aussitôt l'office des morts fut psalmodié. Après cela on se rendit processionnellement vers la chapelle de ND de la Rédemption ; on avait au milieu du sanctuaire creusé un petit caveau et c'est là que furent déposés les précieux restes après que le P. Supérieur eut fait les prières ordinaires et adressé une petite allocution [...]. Il nous le proposa à tous comme un enseignement et un encouragement pour marcher avec constance dans la voie du bien. Vous pensez quelle devait être la joie des congréganistes en possédant dans leur chapelle les reliques d'un saint, et la nôtre en voyant honorés de la translation publique les restes d'un membre de notre chère congrégation. " ${ }^{(51)}$

Mais la légende dorée cellulienne ne serait pas parfaite si, en plus des condisciples et du fondateur, ne se trouvait pas un martyr. Terminons-en avec ces archétypes par celui du prêtre martyrisé en Chine en 1874, Jean-Marie Baptifaud, l'un des premiers crus de l'établissement, qui reste une référence importante pour les élèves tout au long du siècle. Même si Jean-Marie, après son passage à SaintSauveur, intègre le grand séminaire de Montferrand, puis le séminaire des Missions Etrangères... Dès l'annonce de sa mort, Saint-Sauveur s'agite. On s'active, on se renseigne plus avant, on cherche des copies de lettres du martyr. Le Supérieur du grand séminaire de Montferrand est presque aux anges :

"Quelles grâces, quelles bénédictions pour Cellule et pour tout le diocèse ! ; "Si vous êtes à juste titre fier d'avoir élevé un martyr de Jésus Christ, écrit-il au Supérieur de Cellule, nous ne le sommes pas moins [...]. Pour moi, la nouvelle de cette fin, triste aux yeux de la nature mais si glorieuse aux yeux de la foi, m’a causé une profonde émotion, que domine depuis longtemps un sentiment de joie douce et suave." "

Les spiritains, eux, restent plus réservés, plus méthodiques et modestes, en habitués de la gestion du martyre. Dès lors, la mécanique se met en marche, il s'agit de faire connaître Baptifaud, de l'ériger en modèle, pour les élèves et pour l'extérieur. On ne s'étonnera pas de voir un petit scolastique être " chargé » de rédiger sa biographie que l'on publie. ${ }^{(52)}$ On l'associe également aux celluliens moins glorieux, fauchés dans la période, pour faire rayonner l'œuvre par le biais d'un opuscule reprenant la classique thématique des parfums et des fleurs, de ce sicut flos agri cher à tant de congrégations. ${ }^{(53)}$
(50) Émile Roy, petit scolastique, Notes sur la vie et la mort du Frère Elie premier membre de la communauté de Cellule décédé dans cette communauté le 3 septembre I856 et sur la translation de ses restes opérée le 24 juin I864 [1865], (ACSSp, 2 G 10 2a3).

(51) Lettre des petits scolastiques de Cellule aux grands scolastiques, mai 1864, (ACCSp 2 G $102 \mathrm{a} 1)$.

(52) C. Amann, Notice biographique sur M. JeanJoseph-Marie Baptifaud, élève au Petit séminaire de Cellule (I859-1866), Prêtre des Missions Etrangères, décapité à Pien-Kiao, au Yun-Nan (Chine), le I6-I7 septembre 1874, Riom, imp. G. Leboyer, 7 p. C. Amann devient plus tard missionnaire en Sénégambie.

(53) Trois fleurs cueillies en septembre, octobre 
et novembre 1874, par la main du Très-Haut (elles laissent leur parfum à la terre) ou courtes biographies de M. J.J.M.

Baptifaud Missionnaire apostolique décapité au Yun-Nam (Chine), le I6-I7 septembre, $M$. H-E

Fournier, décédé à Glaine

Montaigut, près-Billom,

le 4 octobre, M. A.

Schacherer, scolastique du St Esprit, mort à Cellule le 2 novembre, Riom, imp. G. Leboyer, $1875,32 \mathrm{p}$.

(54) Association des Anciens du Petit séminaire de Saint-Sauveur de Cellule, Compte rendu de la réunion générale $d u$ 7 juillet 1903, ClermontFerrand, impr. Malleval, 1903, p. 68-69.

(55) Bulletin général, tome X, 1874-1877, p. 321. Le Myosotis paraît quatre fois l'an.

(56) Voir respectivement Le Myosotis, $\mathrm{n}^{\circ} 11$, 1er mai 1877 p. 241 et $\mathrm{n}^{\circ} 21,1$ er novembre 1879, p. 6.

(57) Voir Jean Pirotte, "Aux sources des propagandes modernes. L'appel à la mission ", in Gilles Routhier et Frédéric Laugrand, [dir.], L'espace missionnaire. Lieu d'innovations et de rencontres interculturelles, Paris, éditions Karthala, 2002, p. 115-138 ; Richard Drevet, « L'Oeuvre de la Propagation de la Foi et la propagande missionnaire au XIXème siècle ", in Claude Prudhomme, [dir.], Une appropriation du monde. Mission et missions XIXème-XXème siècles, Paris, éditions Publisud, 2004, p. 23-43. Pour une approche locale, voir Francis Koerner,

«Les missionnaires auvergnats à la lumière de leurs lettres et de leurs biographies (XIXèmeXXème siècles) ", Études bourbonnaises, $14 \mathrm{ème}$ série, $n^{\circ} 274$, juin 1996,
Ces biographies édifiantes ne sont pas rédigées uniquement pour être corrigées par les Pères, mais également pour être entendues, puisqu'on les lit à haute voix au réfectoire pendant les repas, aux côtés d'autres lectures pieuses (vies de saints ou du Christ). On veut éveiller à la sainteté par tous les sens. Ainsi, à la mort du jeune martyr Baptifaud, on accrochera une gravure, " un portait peint à l'huile » le représentant, et l'on érige un " modeste monument " dans la chapelle, sous lequel on place une inscription latine vantant les mérites de celui qui a reçu les " palmes du martyre ». Trente ans après sa mort, les anciens celluliens en font toujours un primus inter pares, affirmant que parmi " nos condisciples morts au champ d'honneur, victimes, à la fleur de l'âge, de la barbarie des peuples qu'ils évangélisaient, du climat meurtrier ou de la fatigue [...] notre glorieux martyr Baptifaud est, dans l'autre monde, à la tête d'une innombrable légion. " ${ }^{(54)}$ Quand la gloire d'un seul rejaillit sur tous...

Si l'espace, le temps et la terre sont celluliens, le ciel le devient également au fur et à mesure que l'établissement prend de l'ampleur. Au fil des ans, tandis qu'on construit les bâtiments du séminaire, les élèves, par le biais des biographies qu'ils rédigent, en construisent également l'Au-delà. Plus les années passent, plus le nécrologe de Saint-Sauveur se remplit par les morts et par les écrits des élèves... Communiquer sur les pieuses recrues décédées, c'est affermir la foi des vivantes, c'est à l'extérieur du séminaire comme à l'intérieur faire sa promotion : à Saint-Sauveur, on est petit séminariste jusqu'au bout.

\section{Les anciens : cellulien un jour, cellulien toujours?}

Tout se passe comme si, une fois entré à Cellule, on ne pouvait plus en sortir, comme si le lien scellé l'était pour l'éternité ou du moins pour toute une vie. Pour 
l'affermir, les Pères spiritains ont mis en place en 1874, Le Myosotis, " cette fleur qui est l'emblème du souvenir ", publication imprimée à destination de l'extérieur, rédigée par les élèves et dont les buts sont clairement affichés : " perpétuer dans les rangs [des anciens] le bon esprit de Cellule ».(55)

Les comptes rendus des visites d'anciens celluliens devenus spiritains sont emblématiques. Les aspirants missionnaires ont la chance de voir des modèles en chair et en os, à l'instar de celui revenant des Indes galvaniser les troupes, qui « n'eût garde, à son retour, d'oublier l'établissement où se développa le germe de sa sublime vocation. [...] nous pouvions entourer cet apôtre que Dieu s'était plu à choisir parmi nous, avec tant d'autres qui, [...] portent maintenant la semence évangélique sur toute la terre ", ou de " ces deux glorieux champions de la Foi [qui] ne firent que nous édifier pendant leur court passage ». ${ }^{(56)}$ L'impact de telles visites, véritables bols d'air pour les petits scolastiques et leurs condisciples séminaristes, peut faire tout autant pour déclencher ou fortifier la vocation que les exercices de piété routiniers, l'appel du large séduisant parfois plus que les déclinaisons latines ou les ave maria. On publie également les lettres à leurs familles de missionnaires formés ou passés à Cellule. Il s'agit là encore d'un moyen, simple et proche, de parler au cour de l'élève, d'éveiller en lui la vocation pour la mission et de rappeler aux destinataires extérieurs l'œuvre accomplie. Ainsi les lettres font office de pieux feuilletons visant à entretenir la flamme ; il s'agit là d'un des classiques de la propagande missionnaire. ${ }^{(57)}$ En publiant les lettres de leurs devanciers, les élèves font œuvre de publicité et participent au développement de l'image de «l'enfant prodigue que le souvenir des impressions premières ramène tôt ou tard au bercail ». ${ }^{(58)}$ On est cellulien jusqu'au dernier souffle, à l'instar d'Edgar qui, après être parti de Saint-Sauveur pour l'Infanterie de Marine et la Cochinchine, entre finalement au grand séminaire de Moulins et dont la mort est voulue, par le jeune rédacteur de sa nécrologie, toute tournée vers Cellule :

«C'est là que le Seigneur, satisfait sans doute du jeune lévite, trancha cette existence dans sa fleur. [Edgar] mourut comme on meurt à l'ombre du sanctuaire, et comme dernier témoignage d'affection à la maison qui avait abrité son adolescence, il appela auprès de lui à ses derniers moments les anciens celluliens présents au Grand séminaire et mourut entre leurs bras. " (59)

Par-delà cette propagande, on trouve dans les archives de nombreuses lettres p. 305-323 ; Auguste

Rivet, « Itinéraires missionnaires : le diocèse du Puy XIXème-XXème siècles ", in Gérard Cholvy, [dir.], L'éveil des catholiques français à la dimension internationale de leur foi sgème et zoème siècles, Montpellier, Centre régional d'histoire des mentalités, université Paul Valéry, 1996, p. 61-68 ; Patrick Cabanel, « Les deux Japon. Mémoire et inculcation missionnaire au sud du Massif Central XIXème-XXème siècle ", ibid., p. 91-102.

(58) Le Myosotis, $\mathrm{n}^{\circ} 1$, 1er juillet 1874.

(59) Le Myosotis, $n^{\circ} 24$, 1er août 1880 , p. 105. 
(60) Lettre de l'abbé Gravier, 12 novembre 1885, (ACSSp, 2 G $102 \mathrm{a} 2$ ).

(61) Voir, sur le thème de l'arbre, Dominique Donadieu-Rigaut, « Les arbres ordo ou la complexité des ordres religieux ", Hypothèses 200I. Travaux de l'École doctorale d'histoire de l'université Paris I, 2002, p. $89-101$.

(62) En 1872, la Société des Missions Africaines s'implante à Clermont et fonde, cinq ans plus tard, une école apostolique ; voir l'opus de l'abbé Desribes, directeur de l'établissement, L'évangile au Dahomey et à la Côte des esclaves. Histoire des Missions Africaines de Lyon, Clermont-Ferrand, imprimerie centrale Meneboode, 1877, dans lequel on retrouve nombre de thématiques usitées à Cellule. d'anciens non destinées à la publication, qui informent le Père Supérieur de leurs avancées dans le monde ou dans le sacerdoce. Ce peut être la rencontre d'une jeune fille pieuse (Jean-Jacques, en 1884), l'annonce de la réussite à un examen (Adrien, devenu bachelier ès lettres en 1886), ou une nostalgie pour d'heureuses années, tel ce prêtre écrivant du grand séminaire de Montferrand et évoquant « ce temps si agréable dans les murs de Saint-Sauveur ; tous mes souvenirs sont là ; j’y ai laissé des pères, des amis et je suis sûr que, lorsque j’y retournerai, tous m'ouvriront encore les bras. Je suis sûr que la Mère de la chapelle me sourira toujours, et qu'à ses pieds je retrouverai toutes les douces émotions d'autrefois, et celles plus tristes mais aussi plus profondes et plus brûlantes que j’y éprouvas naguère encore en lui disant adieu, comme à tous mes condisciples aux accents si touchants de ce cantique où nous lui disions en parlant de nos cœurs : gardez-les purs sous l'œil de Dieu ! (60)

Cet intérêt porté aux anciens par les plus jeunes et réciproquement permet d'entretenir l'image de communion-communauté. Ce peut être aussi un utile moyen de continuer à favoriser l'entrain vers Cellule en gardant le lien avec les prêtres diocésains, ex-petits séminaristes, pourvoyeurs éventuels de vocations, et en rappelant aux missionnaires, ex-petits scolastiques, leurs racines, et de leur montrer qu'ils sont une des ramifications de l'arbre spiritain. ${ }^{(61)} \mathrm{Ce}$ peut être aussi un moyen de publicité à une époque où d'autres établissements missionnaires s'implantent dans la région. ${ }^{(62)}$

Les anciens vont colporter dans le diocèse et jusqu'aux antipodes l'idéal cellulien, en reprenant et développant ce qu'ils ont appris, en se souvenant. En juillet 1890, lors d'une rencontre d'anciens dans les murs de Saint-Sauveur, l'un d'entre eux se remémore l'émoi provoqué en lui par une prise d'habits, pour ensuite développer l'image du missionnaire sacrifié, balayé et oublié :

"Les vaillants apôtres s'inclinent encore une fois devant le Dieu de nos autels, et passent au milieu de nos rangs le sourire de la joie sur les lèvres. Ils partent, accompagnés de nos chants et de nos prières, pour la mission lointaine [...]. Qu'espèrent-ils donc trouver là-bas sur ce sol brûlant de la terre d'Afrique, sous ce climat meurtrier du Tropique ? La pauvreté, souvent même la misère sera leur partage. L'ingratitude répondra à leur dévouement. Chaque jour apportera à leur cour une déception, une épreuve nouvelle. Sans cesse se dresseront devant eux, menaçantes et cruelles, les maladies et la 
mort. Après leur douloureux trépas, une croix de bois marquera seule l'endroit où reposent leurs restes inanimés, jusqu’au jour où des événements subits, peut-être même le caprice des hommes viendront emporter ce dernier souvenir de leur passage et de leurs sacrifices. Voilà ce qui les attend. Ils le savent et cependant ils partent la joie dans le cœur et le bonheur dans l'âme. N'est-ce point là l'héroïsme de la vertu porté au degré le plus sublime? Saluons la Croix qu'ils portent sur leur poitrine : elle est entourée d'une auréole de gloire devant laquelle pâlit celle de nos héros du siècle. Soyez fiers [...] d'appartenir à une famille qui compte tant de héros [...]. »

Et le rédacteur de rappeler « les liens de l'amitié fraternelle qui nous unit [...] gage de l'éternelle félicité ». ${ }^{(63)}$

On a là en quelque sorte le but symbolique ultime de Cellule : non seulement former des hérauts de l'Évangile et des héros de la mission, mais, au final, fabriquer d'obscurs martyrs potentiels dont seuls se souviendront les anciens condisciples, comme l'affirme un poème spiritain plus tardif :

"Chez nous, pas d'éclatant, de triomphal martyre / Que l'Église enregistre et que va signer Dieu, / Mais l'agonie obscure et lente... à petit feu, / La mort qui vient sournoise et sûre, sans rien dire / Ah ! combien sont tombés qui n'avaient pas trente ans. " ${ }^{(64)}$

Si aujourd'hui la chose peut éventuellement étonner, elle est cependant assez classique d'un catholicisme congréganiste, missionnaire ou non. Si la mission est consubstantielle du christianisme, le martyre, en sa version catholique du XIXème siècle, l'est également. Être martyr, témoigner jusqu'au bout, pour reprendre l'évangéliste (Lc 12,8), c'est rehausser en souffrant de maladie ou de divers déboires ses perspectives dans l'économie du salut, c'est se donner et donner à l'établissement une réputation, c'est être éducateur. Par son sacrifice seul, loin des siens, dans une contrée hostile, le missionnaire cellulien édifiera des promotions entières d'élèves de Saint-Sauveur, même si on ne trouvera pas trace de nécrologie le concernant dans les devoirs de ses petits successeurs. Que l'on se destine au sacerdoce diocésain ou à la mission, tout le monde souffre. Du petit séminariste mourant de tuberculose au cellulien décapité, de l'enfant délirant sur son lit de douleur au Père emporté par la fièvre sur la « terre de Cham ", tout le monde doit souffrir pour l'amour et la gloire de Dieu, en attendant la récompense céleste. La mission est souffrance, la mission est sacrifice. ${ }^{(65)}$
(63) Association des

Anciens du Petit séminaire de Saint-Sauveur, Compte rendu de la réunion générale du i6 juillet I89o, Riom, impr. U. Jouvet, 1891, p. 6-7.

(64) Georges Goyau, Clergé colonial..., op. cit., p. 276.

(65) L'image n'est pas que symbolique, la Mission dévore. Ainsi, sur les 54 pères envoyés par la Société des Missions Africaines en pays Yoruba, 44 meurent dans les trois années suivant leur arrivée (voir Bernard Salvaing, Les missionnaires à la rencontre de l'Afrique au XIXème siècle, Paris, L'Harmattan, 1994, p. 145). Joseph Michel note que, « jusqu'en 1920, la moyenne de vie apostolique des prêtres missionnaires de pays africains comme le Congo ou le Dahomey ne dépassait pas trois ans ", in Missionnaires bretons 
d'outre-mer aux XIXème et

XXème siècles, Rennes,

Presses universitaires de Rennes, 1997, p. 254.

(66) Calcul réalisé à partir des indications données dans les diverses livraisons du Myosotis entre 1874 et 1887 $(n=335)$.

(67) Bulletin général, tome XI, 1877-1881, p. 159.

(68) « Le P. Hubert, ancien Supérieur du PetitSéminaire de Cellule ", Semaine religieuse de Clermont, $\mathrm{n}^{\circ} 2,13$ janvier 1906, p. 36.

(69) Annales des Missions Etrangères, 1921, p. 80. Autre exemple avec Mathieu Lafarge qui, après quatre années de vicariat dans le diocèse, s'engage chez les Oblats de Marie Immaculée et part pour Ceylan ; voir « Notice nécrologique. R.P. Lafarge, O.M.I. ",
La mécanique mise en place semble offrir des résultats satisfaisants tant pour le diocèse que pour la congrégation. Sur les élèves ayant terminé leur dernière année à Cellule entre 1862 et 1879 , près des trois quarts proviennent du diocèse de Clermont et près des trois quarts également endossent les «livrées du Christ ». ${ }^{(6)}$ Dans leurs rapports à la Maison-Mère, les spiritains notent que " depuis plusieurs années déjà le nombre de jeunes gens que la maison de SaintSauveur donne au grand séminaire égale et quelquefois même dépasse le chiffre que fournissent les trois autres maisons ecclésiastique du diocèse. [...] Ce qui contribue beaucoup à attirer ces vocations vers l'Institut, ce sont les relations de confraternité qui existent entre les deux œuvres du petit séminaire et du scolasticat ". ${ }^{(67)}$ Coup double reconnu par la Semaine religieuse de Clermont qui, lors de la mort du Père Hubert, pilier de l'établissement de 1859 à 1887, affirme que "par [son] apostolat, [il] a suscité et préparé pour la sainte Église plus d'un millier de prêtres, de Frères, de Religieuses, qui travaillent au service de Dieu et au bien des âmes dans divers diocèses, notamment dans celui de Clermont, et surtout dans les Missions et les Colonies $»{ }^{(68)}$

On peut se demander si certains petits celluliens originellement destinés au diocèse n'ont pas été contaminés par l'ardeur missionnaire qui régnait dans l'établissement de leurs débuts. On trouve en effet plusieurs exemples de prêtres qui, après être passés par Cellule et le grand séminaire du diocèse, s'engageront dans des congrégations missionnaires, tel Pierre-Etienne Bachelard, passé aux Missions Étrangères, dont la biographie établie par cette congrégation plus asiatique qu'africaine rappelle le passage par Cellule, où il « entend les élèves dire et répéter comme des mots de passe : "au Gabon, au Congo !" ", et ses hésitations : " peut-être aussi cherchait-il sa voie et hésitait-il entre la Rue du Bac [siège des Missions Etrangères] et Chevilly [grand scolasticat spiritain] ". ${ }^{(69)}$ Certains celluliens, n'ayant pas persévéré dans leur vocation, partiront également pour les terres lointaines, pour finir commerçant au Brésil, médecin militaire à Hanoï ou peintre à la Nouvelle-Orléans, les schémas d'émigration typique des Auvergnats, Aveyronnais ou autres Lozériens du XIXème siècle se mêlant au désir d'ailleurs inculqué par les Pères missionnaires.

Si le jeune cellulien est formé à la répétition de gestes, à l'apprentissage d'un habitus liturgique, ${ }^{(70)}$ si le latin d'Église lui inculque des schémas de pensée, s'il est théoriquement sans cesse sous la houlette des pères, il est également 
amené à se fabriquer des envies et des idéaux sacerdotaux, généralistes pour les futurs prêtres diocésains ou spécialisés pour les missionnaires, en se positionnant sur une gamme sacrificielle. Si l'institution peut répondre tant à sa vocation qu'à ses hésitations en l'accompagnant et en le préparant à arpenter le sentier du sacerdoce, si tout est fait pour l'amener à accepter l'attirail réglementaire du petit séminaire et à s'y plier de bon cœur, il devra surtout apprendre à s'insérer dans une lignée obscure pour le prêtre diocésain ou dans le continuum congréganiste pour le Père spiritain, sans grand espoir de satisfaction terrestre. Durant une partie de son enfance et pendant son adolescence, il (s') est entraîné à revêtir les livrées sacerdotales. Il s'est créé une terre, un espace et un temps, véritables havres de paix. Il s'est également préparé un ciel rempli de glorieux ou d'obscurs anciens et de petits camarades côtoyés sur les bancs de l'établissement. Durant sa carrière future, Cellule lui permet de se retremper et de se rappeler à lui-même le fondement de sa vocation, ce que note d'ailleurs le martyr Baptifaud dans la lettre qu'il adresse au Supérieur de l'établissement avant son départ pour l'Asie : "Quelque part que la Providence me transporte, c'est à Cellule que je viendrai par la pensée me rafraîchir l'âme. " "(1) Si l'on pousse la logique à l'extrême, on peut presque dire qu'après sa mort, dans l'Au-delà qu'il s'est créé et qu'il entend habiter, l'ex-petit cellulien retournera à Saint-Sauveur. Parvulus cellulianus ad aeternum, enfant de Cellule pour l'éternité... ${ }^{(72)}$
Semaine religieuse de

Clermont, $\mathrm{n}^{\circ} 29,17$ juillet 1909 , p. 626-627.

(70) Pour reprendre la formule de Charles Suaud, La vocation..., op. cit., p. 90.

(71) Lettre au Révérend Père Supérieur,

21 novembre 1871 ,

(ACCSp, 2 G 10 2a2).

(72) Les spiritains ferment l'établissement en 1968, " raison oblige », écrit le Supérieur provincial, lui-même ancien enfant de Cellule ; voir François Morvan, «Visite canonique du 28 mai 1968 ", Cahiers des comptes rendus des visites provinciales 1938 -I968, (ACSSp, 2 G 10 7a). 